\title{
СОВРЕМЕННЫЕ ПРОБЛЕМЫ ЛОГИСТИКИ И ПУТИ ИХ РЕШЕНИЯ
}

\section{Соколов А.М.}

Экономика

г.о. Кашира Московской области,

ГБПОУ МО «Ступинский техникум им. А.Т. Туманова», 2 курс

Научный руководитель: Сарычева Е.А.,

г.о. Ступино Московской области

ГБПОУ МО «Ступинский техникум им. А.Т. Туманова», преподаватель. Ключевые слова: логистика, проблемы, решения, отсутствие, запасы, товар, путь, транспорт, система, снабжение, заказ, склад, инфраструктура, спрос, материалы, предприятия, сервис, эффективность, материалы, дифференциация.

\section{Введение.}

Актуальность исследования заключается в том, что в настоящее время эффективная логистика и транспортная система являются важными предпосылками развития любой экономики. В современной конкурентной среде недостаточно предлагать продукт, отвечающий требованиям клиентов, одним из важнейших аспектов логистических процессов является способ его доставки. Быстрая и качественная доставка товаров может помочь предприятиям работать более эффективно, снизить затраты и привлечь новых клиентов.

Логистика развивалась на протяжении веков, чтобы стать неотъемлемой частью любого бизнеса. Было время, когда компании сами разрабатывали ассортимент продукции, планировали ее сбыт, разрабатывали маркетинговые системы и сами доставляли готовый продукт розничным продавцам. Однако с начала 1990-х годов логистические операции стали намного сложнее. Мировой рынок логистики радикально вырос за эти годы.

Логистика берёт свои корни из истории Византии IX века нашей эры. В те времена она применялась в военном деле, её задачей была четкая, слаженная работа тыла по обеспечению войск всем необходимым. 
В России термин логистика появился в середине XIX века, как искусство управления перемещением войск вдали и вблизи от неприятеля, организация их тылового обеспечения во время боевых действий.

Со временем логистика поменяла своё значение и задачи. Сейчас логистика предстаёт перед нами, как область экономической деятельности, предмет которой заключается в организации рационального процесса продвижения товаров от производителя к потребителю, функционирования сферы обращения продукции, товаров, услуг, управления товарными запасами, создания инфраструктуры товародвижения.

Проще говоря, логистика - стратегическое управление цепью поставок. Этот процесс должен быть рациональным. Отрасль растет благодаря двум факторам: развитию мировой экономики и научно-технического прогресса (введение робототехники). Потребности клиентов растут, поэтому необходимо внедрять новые способы насыщения рынка товаров.

Логистика сегодня стала жизненно необходимым компонентом современной экономики. Свою актуальность приобрела за счёт возможности повышения эффективности функционирования материалоперевозящих систем с помощью планирования. В основе деятельности лежит мощная информационная система, которая интегрирует нормы по управлению данной категорией товаров.

Соответственно, логистика является одной из сфер, которые все еще имеют потенциал в плане повышения производительности.

Проблема исследования заключается в том, что существуют большие неиспользуемые мощности в логистических процессах с точки зрения снижения затрат и качества обслуживания, которые необходимо решать системно, рационально, но учитывая дифференцированный подход.

Объект исследования - проблемы современных логистических процессов.

Предмет исследования - определение оптимальных путей решения проблем современных логистических процессов. 
Цель нашего исследования - изучение проблем современной логистики и системный подход в их решении.

\section{Задачи исследования:}

1. Определить основные преимущества эффективных логистических операций.

2. Дифференцировать и проанализировать виды логистики.

3. Обозначить общие проблемы логистики в целом.

4. Детально проанализировать проблемы каждой отрасли логистики.

5. Предложить возможные пути решения по выявленным проблемам.

\section{1.Сущность эффективности логистических операций.}

Основные преимущества эффективных логистических операций можно определить следующим образом:

- Экономия средств за счет централизации управления запасами.

- Ускоренное выполнение заказов благодаря глобальной транспортной сети.

- Оптимизация денежных потоков.

- Гибкость в изменении системы распределения новой продукции на основе постоянно меняющихся требований клиентов.

Из выше сказанного мы можем определить следующие основные сегменты рынка, обслуживаемые отраслью логистики:

- Услуги экспресс-доставки посылок и документов.

- Грузовые перевозки воздушным, морским, автомобильным или железнодорожным транспортом.

- Складирование и распределение.

- Систематизирование и актуализация цепей поставок.

Современная логистическая система включает следующие элементы:

- Транспорт — этот элемент, как и остальные, сам является сложной системой. Он включает в себя материально-техническую базу, с помощью которой транспортируются грузы, а также инфраструктуру, обеспечивающую ее функционирование. 
- Склады - здания, сооружения, устройства и т.п., где временно размещаются и хранятся материальные запасы, преобразуются материальные потоки.

- Обслуживание производства (в производственных логистических системах) - подразделения логистики, занятые обслуживанием процесса производства.

- Сбыт - подсистема, которая обеспечивает выход материального потока из логистической системы.

- Информация - подсистема, которая обеспечивает информационную связь между другими элементами логистической системы, контролирует выполнение логистических операций, а также решает ряд других задач.

- Запасы - запасы материалов, которые позволяют данной системе быстро реагировать на изменение спроса, обеспечивают равномерность работы транспорта, а также помогают решать ряд других задач в логистических системах.

- Сервис - система обеспечения, позволяющая покупателю и (или) потребителю выбрать оптимальный вариант приобретения и потребления товара.

- Закупка - подсистема, которая обеспечивает поступление материального потока в логистическую систему.

- Кадры - организованный персонал, занятый выполнением логистических операций.

\section{1. Виды логистики.}

Исходя из вышеперечисленных элементов выделяют следующие виды логистики:

1. Транспортная логистика, которая изучает организацию грузоперевозок от поставщика до потребителя, с предприятия на склад, со склада на склад, со склада до потребителя; в этой области решаются задачи выбора транспортных средств, наиболее рационального способа перевозки, 
сочетающего минимальные издержки, максимальную скорость, надежность и удобство для потребителя.

2. Складская логистика, которая занимается организацией складской грузопереработки: размещением материалов в складских помещениях для хранения, управлением складской переработкой, упаковкой, погрузкойразгрузкой, формированием оптимальных по размеру партий грузов, организацией товарного хозяйства, выбором схемы размещения складов и др.

3. Производственная логистика, которая занимается управлением материальными потоками внутри предприятий, создающих материальные блага или оказывающих такие материальные услуги как хранение, фасовка, развеска, укладка и другие.

4. Сбытовая (распределительная) логистика, которая предстаёт функциональным продолжением внутрипроизводственной логистики и формирует самостоятельную область логистики, цель которой заключается в обеспечении продвижения готовой продукции в сопровождении сервиса от производителей до потребителей, в том числе промежуточных и конечных.

5. Информационная логистика организует информационные потоки внутри предприятия, а также обмен информацией между различными участниками логистических процессов, находящихся на значительном расстоянии друг от друга.

6. Логистика запасов, занимающаяся вопросами формирования оптимальных размеров запасов материальных ресурсов на предприятии. Запасы продукции позволяют данной логистической системе быстро реагировать на изменение спроса и обеспечивают равномерность работы транспорта.

7. Логистический сервис представляет собой комплекс услуг, которые оказываются производителем или экспедиторской фирмой, занимающейся логистическим сервисом, в процессе доставки материальных ресурсов потребителю. 
8. Логистика запасов (снабжения) занимается управлением и организацией запасов на складах, а также контролирует издержки на складские операции.

9. Кадровая логистика - это раздел логистики, занимающийся оптимизацией потоков трудовых ресурсов предприятий и отрасли в целом.

Но, как и у любой экономической деятельности, у логистики есть определённые проблемы.

\section{2. Общие проблемы логистики и пути их решения.}

Рассмотрим общие проблемы логистики и определим пути решения.

1. Проблема административного толка, появляющаяся ввиду отсутствия отдельного ведомства, которое занималось бы вопросами логистики, что в свою очередь может привести к последующей деформации логистической инфраструктуры и сдерживанию развития логистического бизнеса.

2. Кадровый вопрос, в настоящее время существует нехватка квалифицированных специалистов, имеющих не только теоретические знания в области логистике, но и опыт практической работы в этой сфере.

3. Использование устаревших, а вернее, неиспользование современных технологий, что приводит к проблемам с идентификацией продукта, путаницей на складах и замедлению доставки товара.

4. Проблемы руководящего звена, возникающие в частом непонимании руководством чёткого представления о месте, которое занимает логистика в структуре компании.

5. Нерациональное развитие системы распределения товаров и услуг, то есть отсутствие общей стратегии развития систем распределения и недостаток организованных товарных рынков на уровне крупного и среднего опта.

Пути решения:

1. Проведение анализа кадровой политики и подготовка квалифицированных специалистов логистической отрасли, которые будут 
определять особенности организации процессов внутри логистической компании.

2. Усовершенствование процессов логистической деятельности, а именно процессов отслеживания, маркировки, транспортировки, распределения и складирования продукции.

3. Системное внедрение современных цифровых и информационных технологий в логистические процессы.

3. Дифференциация проблем по видам логистики и пути их решения.

\section{Проблемь, свойственные транспортной логистике:}

1. Одной из глобальных проблем в транспортной логистике является отсутствие развитой и современной транспортной инфраструктуры в некоторых регионах страны.

2. Неправильно построенные маршруты доставки готовой продукции и нерациональное использование транспортных средств при перевозке грузов.

3. Несоблюдение водителем графика и маршрута движения.

4. Слабая инфраструктура транспорта, прежде всего в области автомобильных дорог; недостаточное количество грузовых терминалов, а также их низкий технико-технологический уровень.

5. Отсутствие практически на всех видах транспорта современных технических средств, отвечающих мировым стандартам; высокая степень физического и морального износа подвижного состава транспорта.

6. Неэффективное использование собственного и наемного подвижного состава.

7. Потери от простоя в ожидании погрузки/выгрузки транспортного средства (ТC).

Все перечисленные проблемы приводят к более длительному сроку доставки груза от производителя покупателю, перерасходам горюче- 
смазочных материалов, увеличению временных и денежных затрат. Также создают угрозу для перспективного развития транспортной системы в целом, что, замедляя общеэкономический рост России, ослабляет ее позиции на мировом рынке и затрудняет развитие отдельных транспортных предприятий.

Пути решения:

1. Необходимо проводить систематический и своевременный мониторинг и анализ состояния транспорта и автодорожного полотна, реально оценивать возможности.

2. Необходимо выявить проблемные зоны использования транспорта в обеспечении безотказности и безопасности его передвижения, и в качестве основных критериев оптимизации выбрать минимизацию стоимости перевозки и максимизацию коэффициента использования пробега.

3. Анализ и жёсткий контроль за соблюдением графика и маршрута передвижения груза посредством систем GPS и ГЛОНАСС.

4. Увеличение финансирования для обновления и введения инноваций в парк подвижного состава, автодорожного полотна, постройки и улучшения технико-технологического уровня грузовых терминалов.

5. Увеличение эффективности использования транспортных средств за счёт правильного выбора маршрута и автоматизации погрузки-разгрузки груза.

\section{Проблемь, свойственные складской логистике:}

1. Перепроизводство складов - ситуация, когда поступает больше товаров, чем склад может вместить и отгрузить, в результате это приводит к лишним затратам времени и рабочей силы (колебание спроса покупателей и требование заказчика).

2. Лишние операции и перемещения - расположение товара не там, где удобно, а там, где есть место.

3. Длительное время ожидания при приёмке, сборке и отгрузке товара, что приводит к издержкам склада. 
4. Отсутствие адресного хранения вызывает ошибки подбора, недопоставки, пересортицу.

5. Недостаточное количество грузовых терминалов и складских помещений.

6. Устаревшая материально-техническая база складов. Пути решения:

1.Реальная оценка поступления количества товаров на склады или укрупнение складов.

2. Создание оптимальной системы складирования и адресного хранения товара посредством введения новых логистических компьютерных программ.

3. Сокращение времени ожидания при приёмке, сборке и отгрузке товара путём ускорения обработки информации и принятия решения сотрудниками склада, координация действий между работой погрузчиков и операторов склада.

4. Увеличение финансирования, путём привлечения сторонних инвестиций, для обновления и модернизации складских помещений, а также материально-технической базы.

\section{Проблемы, свойственные производственной логистике:}

1. Дефицит необходимого материала на складе снабжения, что приводит к сбою производственных процессов и потере прибыли, на производстве, для которого предназначался данный продукт.

2. Неэффективная система управления качеством продукции, что приводит к снижению сбыта и имиджа предприятия.

3. Огромная длительность производственного цикла изготовления партии изделий, что приводит к максимальным затратам живого труда, материальных, финансовых и временных средств.

Пути решения:

1. Научиться управлять дефицитом необходимого материала на складе снабжения, посредством максимальной автоматизации снабжения. 
2. Повышение эффективности управления качеством продукции путём обеспечения необходимыми материальными, финансовыми и трудовыми ресурсами.

3. Сокращение длительности производственного цикла изготовления партий изделий путём автоматизации и роботизации.

\section{Проблемы, свойственные информачионной логистике:}

1. Отсутствие сбора информации на предприятиях. В основном информация носит неточный, неоперативный и непреемственный характер. Зачастую компании терпят крах по причине несвоевременной, либо недостоверной полученной информации.

2. Слабое развитие коммуникационных сетей по структуре и техническому уровню для информационных систем обслуживающих ЭВМ и отсутствие информационного взаимодействия между поставщикамипроизводителями и покупателями-потребителями.

3. Отсутствие технических средств информационного обеспечения на предприятиях.

4. Отсутствие единой межнациональной коммуникационной информационной системы, которая была бы способна передавать информацию о материальных потоках и осуществлять контроль за их продвижением.

Пути решения:

1. Привлечение инвестиций для установки современного технического обеспечения на предприятии.

2. Развитие коммуникационных сетей на предприятии путём обеспечения развития у сотрудников чисто технических навыков коммуникации, например, таких как: умение пользоваться электронной почтой, факсом и т.д.

3. Введение единой межнациональной коммуникационной информационной системы. 
4. Создание отраслевых и внутрипроизводственных центров, которые будут управлять одновременно информационными и материальными потоками на предприятии.

Проблемы, свойственные для логистического сервиса:

1. Высокие совокупные затраты, связанные с обслуживанием и содержанием запасов.

2. Высокая себестоимость товаров и услуг.

3. Низкие надежность обслуживания и готовность к выполнению заказов и запросов потребителей логистических услуг.

4. Отсутствие маркетинговых стратегий функционирования транспортного комплекса.

5. Низкое качество логистического сервиса, не отвечающего европейским и мировым стандартам.

6. Низкий уровень развития производственно-технической базы, инфраструктуры сервиса, информационных систем поддержки транспортно логистического процесса.

7. Отсутствие современных логистических технологий транспортноэкспедиционной деятельности.

Пути решения:

1. Снижение совокупных затрат путём применения аутсорсинга и аутстаффинга.

2. Для понижения высокой себестоимости товаров и услуг следует повысить производительность труда, автоматизировать производство и внедрить инновационные технологии.

3. Повышать надёжность обслуживания и готовность к выполнению заказов и запросов потребителей логистических услуг, учитывая разницу в покупательской способности и индивидуальными предпочтениями.

4. Необходимо увеличить количество распределительных центров (оптовых складов). 
5. Оптимально разместить эти склады на обслуживаемой территории.

6. Создать оптимальный парк транспортных средств требуемой грузоподъемности и рационально организовать его работу по доставке продукции предприятия от места производства до места потребления.

7. Необходимо наладить прямые связи с потребителями продукции предприятия.

8. В то же время, никоим образом нельзя терять уже наработанных связей с оптовыми покупателями, а предложить им и в дальнейшем работать на взаимовыгодных условиях.

Проблемы, свойственные для логистики запасов:

Основная проблема логистики запасов заключается в нахождении компромисса между двумя противоречивыми принципами: с одной стороны, сокращение размера запасов, с другой - недопущение дефицита и обеспечение бесперебойности снабжения.

Путь решения:

Внедрение информационных систем, основанных на прогнозировании потребительского спроса, планировании запасов, анализе времени выполнения заказов, оборачиваемости заказов.

Проблемы, свойственные для закупочной логистики:

1. Основная проблема заключается в неналаженном функционирование закупочной логистики, так как многие фирмы продолжают работать, ориентируясь на времена, когда все ресурсы в стране не закупались, а распределялись.

2. Отсутствие необходимого товара в нужный момент или его дефицит.

3. Наличие избыточных запасов товаров на складе готовой продукции (материалов).

4. Срывы поставок из-за транспортных компаний и отсутствии внутренней дисциплины. 
5. Большое количество ручных операций и дублирований среди снабженцев компании.

6. Отсутствие претензий поставщикам, с предъявлением всех затрат и издержек фирмы (обычно просто проводится уменьшение заказа или проводится обмен товара, который оказался испорченным).

7. Отсутствие автоматизированных средств оптимизации закупаемого товара (особенно актуально для торговых компаний).

8. Откатные технологии работы с поставщиками.

Пути решения:

1. Разработка или приобретение автоматизированной системы прогнозирования и планирования поставок товара.

2. Оптимизация и регламентация процессов закупки в соответствии с международными стандартами логистики.

3. Разработка системы мотивации персонала службы закупок на результат.

4. Введение процедуры непрерывного совершенствования процессов производства, вспомогательных бизнес-процессов и управления (процедура «кайдзен»).

5. Разработка противооткатных схем в закупках: например, разбить цикл закупки (планирование, выполнение, контроль и анализ) по различным отделам.

\section{Проблемы свойственные для кадровой логистики:}

Основной проблемой кадровой логистики является нехватка квалифицированных специалистов.

Путь решения:

Привлечение логистических предприятий, являющихся стратегическими партнёрами высшего и среднего профессионального образования, в образовательный процесс путём дуального образования: теоретическая часть подготовки специалистов проходит на базе образовательной организации, а практическая - на рабочем месте. 


\section{4. Заключение.}

Современный мир движется путём информатизации и цифровизации, исходя из этого любая сфера деятельности человека должна актуализироваться под современные стандарты в большей степени это касается экономической деятельности современного общества. Общество желает получать высокочественную продукцию и услуги, поэтому логистические процессы в экономической деятельности должны отвечать современным требованиям. Для этого необходимо решать вопросы отраслевой логистики не только дифференцированно, но и применять системный подход для достижения более эффективных и рациональных процессов. Исходя из этого важно рассматривать и проблемы, и пути их решения в совокупности, не исключая ни единого звена этой цепочки.

\section{Список использованной литературы.}

1. https://studfile.net/preview/2824610/page:10/

2. https://vuzlit.ru/310136/ponyatie_logisticheskoy_s...

3. https://www.bestreferat.ru/referat-375856.html

4. https://cwetochki.ru/ref-shpargalka-shpargalka-po-...

5. https://vuzlit.ru/740113/harakteristika_elementov_...

6. https://cwetochki.ru/ref-referat-logistika-poniati...

7. https://vuzlit.ru/1997322/suschnost_logistiki

8. https://studfile.net/preview/1864914/page:4/

9. https://studopedia.ru/10_267345_teoreticheskaya-ko...

10. http://www.alogistika.ru/theory/4/63.htm

11. https://studopedia.su/10_128919_problemi-informats...

12. https://studfile.net/preview/5176327/

13. https://studfile.net/preview/5176088/page:47/

14. https://studopedia.su/12_10108_ponyatie-i-sushchno...

15. https://studwood.ru/1300342/ekonomika/problemy_inf...

16. https://revolution.allbest.ru/transport/00423053_0...

17. https://studfile.net/preview/5793428/page:4/ 
18. https://lektsii.org/1-10595.html

19. https://www.bestreferat.ru/referat-113042.html

20. https://studopedia.ru/2_92568_sushchnost-logistiki... 